\title{
Decision-making in complex environments
}

under time pressure and risk of critical irreversibility:

The role of meta rules

Sophie LE BRIS, French Naval Academy - LEGO (University of Western Brittany), France

Email: sophie.le bris@ecole-navale.fr

Antonia MADRID-GUIJARRO, Universidad Politécnica de Cartagena (UPCT), Murcia, Spain

Email : antonia.madrid@upct.es

Dominique Philippe MARTIN, Université Rennes, CREM UMR 6211, CNRS, France

Email : dominique.martin@univ-rennes1.fr

\section{Acknowledgments}

The authors would like to thank the anonymous reviewers, Laure Cabantous and Thomas Roulet for their helpful comments that improved this paper. All errors and omissions are, of course, the authors'.

This document is in line with the work that will be developed by the "Resilience \& Leadership" Chair of the French Naval Academy and the University of Western Brittany in partnership with the University of Rennes, BFM, Safran and Naxicap. 
Abstract:

In complex situations with risks of critical irreversibility, decision-makers must be able to take action quickly but also appropriately, especially in response to unexpected events. In these situations "the first error in the trial-and-error-learning will also be the last trial" (Weick \& Sutcliffe 2011: 20). This paper assesses the contribution of the meta rule concept defined as the conditions to respect to maintain the integrity of the organization in an unexpected situation. Our design tests the relevance of two conceptual approaches: High Reliability Organizations (HRO) and the sensemaking approaches. The main proposal of this research is to highlight that, for a decision-maker, understanding a situation through meta rules at key times limits the risk of information overload by facilitating an overall understanding of the situation. It becomes possible to make decisions quickly, if necessary, using new robust and reliable strategies. Using a quantitative study of warship bridge team behaviors composed of cadets in the French Naval Academy, the authors tested various situations that young officers have to manage. The results highlighted that meta rules play a positive mediating effect between rules and reliability and between interactions and reliability. With the use of meta rules, the overall reliability level is higher employing a HRO approach than using a sensemaking approach.

Keywords: reliability - meta rules - decision-making - French Naval Academy - complexity 


\section{Introduction}

Numerous studies have highlighted the difficulties of decision-making in unexpected or highly complex situations (Klein, 1999; Lipshitz, et al., 2001; Rosen, et al., 2012). While these situations can be sources of learning that allow for identifying new opportunities (Dahlin, et al., 2018), they can also be a source of error or failure.

This is especially the case for High Reliability Organizations (HRO) - i.e., "a family of organizations that operate continuously under trying conditions and have fewer than their fair share of major accidents" (Weick \& Sutchiffe, 2007; Saleh, et al., 2010) - where the "first error in the trial-and-error-learning will also be the last trial" (Weick \& Sutcliffe, 2011).

A central concern for HRO is, therefore, the identification of signals that enable the decisionmaker to switch from a "sequence of subroutines in a familiar work situation", also known as rule-based behavior (Rasmussen, 1983), to a sequence of knowledge-based behaviors (Rasmussen, 1983). This latter type of behavior, however, comes with specific challenges. For instance, when people have to deal with new information, their decision-making is slowed down even though the situation may require quick actions. In addition, the construction of a new understanding of the environment raises the issue of the legitimacy of the decision about rules (Kœnig, et al., 2016), as illustrated in the Fukushima nuclear power plant case where the director deliberately ignored all formal procedures (Guarnieri \& Travadel, 2018) to act according to his understanding of the situation.

In this article we seek to answer the following question: how to improve the reliability of decision-making in complex environments under time pressure and with a risk of critical irreversibility?

So far, organization scholars have dealt with this question in two ways. On the one hand, the High Reliability Organizations (HRO) literature shows that reliability relies on strict 
compliance with rules and norms (Roberts, 1990) and, therefore, the emphasis is put on rulebased behaviors which are representative of command-and-control actions (Leveson, et al., 2009). On the other hand, the sensemaking approach underlines the central role of interactions enabling actors to co-construct a shared representation of the environment when they are confronted with complex, uncertain situations (Bierly \& Spender, 1995; Ouchi, 1980; Weick, 1993). This approach, hence, puts the emphasis not on rules but instead on knowledge-based behaviors, which are said to be required in unexpected contexts and situations.

Although the differences between rule-based behaviors and knowledge-based behaviors have been widely studied, the conditions under which one switches from one modus to another are still the subject of many questions. Thus, how is it possible to maintain a "reluctance to simplify and sensitivity to operations" (Weick \& Sutcliffe, 2006) while keeping an overview of the driven processes? Similarly, how can the tension between an "enriched awareness" (Weick \& Sutcliffe, 2006) and the mechanisms of close coordination required by a naval base, warship or nuclear power station be solved? Finally, how to deal with the unexpected and provide a reliable response mode when the decision-maker is not an expert, which is presupposed in the HRO and sensemaking approaches?

This paper offers some possible answers to these questions by mobilizing the concept of meta rules. On initial examination, meta rules focus on the conditions to respect the integrity of the organization to manage in unexpected situation. Our proposition is that using meta rules makes it possible to ensure the sustainability of the action by putting back the choice and the use of rules in a holistic vision. Meta rules constitute a first basis of knowledge-based behavior in complex contexts characterized by "time stress" (Klein, 1999) and risk of "critical situations" (Endsley, 2001). They do not directly describe the modus operandi of the HRO. They also differ from heuristics that can be associated with success but also with failure (bias), possibly leading to dramatic consequences (in terms of our study, this would lead to sinking, human losses, etc.) 
(Elstein, 1999; Maitland \& Sammartino, 2015). The meta rules enable decision-makers to (re)prioritize, if necessary, the rules with the objective to maintain the integrity of the organization to manage.

In the following paragraphs, we will use the acronym CTI to qualify situations with Complexity (C), Time pressure (T) and risks of critical Irreversibility (I). If these features are tense for any organization, they are specifically crucial for HROs. They correspond to a set of specific and varied real objects, such as safety in nuclear power plants or in operation rooms, aircrafts, submarines and also war vessels, justifying our field of study as presented below.

Through the study of bridge team behaviors composed of cadets from the French Naval Academy, our paper tests various situations that young officers have to manage. We tested a series of propositions around the value of meta rules, which we argue can limit the risk of information overload by facilitating an overall understanding of the situation when used at key moments. Our results highlight the relevance of meta rules in situations that require rapid action. For a decision-maker, it becomes possible to decide quickly, if necessary, which new strategies will be robust and reliable.

Our paper is structured as follows. We first present the theoretical background (section 2) before providing an analysis model (section 3). In sections 4 and 5, we detail the methodology and our research findings. We discuss the implications of these findings in section 6 and conclude with an overview of some study limitations and avenues for further research.

\section{Theoretical background}

\subsection{Reliability of HROs and sensemaking approaches}

\subsubsection{Reliability of current HRO}

Roberts (1990), in her analysis, spotlights the technological dimension of HROs (High Reliability Organizations). They are technologically complex and their technologies are highly 
interdependent. These organizations also have a high damage potential, but errors happen relatively rarely. She illustrates that in the case of a nuclear aircraft carrier study (US naval forces) (Roberts, et al., 1994) "One indicator that the carriers are highly reliable is that there has not been a deck fire attributable to anything other than the cost of doing battle since 1969 . Another indicator of extraordinary reliability is the U.S. Navy's aircraft accident rate. A "crunch" occurs when two aircrafts touch while being moved on either the flight or hangar decks. In 1989 the overall crunch rate for nuclear carriers was approximately 1 in 8,000 moves”. In a more thorough analysis, Rochlin (1996) and Bourrier (1999) emphasize five main factors of HROs; a redundancy of the decision-making channels (factor 1) associated with a redundancy of control between the actors (factor 2) (Laporte \& Consolini, 1991), training and retraining by repetition of incident scenarios that actors have never had to face (factor 3 ) (Roberts, 1990), an agreement on the final goals within the organization (factor 4) (Laporte \& Consolini, 1991), and lastly (factor 5) a focus on decision-making processes with a centralization at strategic levels and a decentralization at operational levels when circumstances require them. These five factors constitute the basis of a culture of reliability for the current HRO. These organizations are hierarchical but contain various formal and informal networks (Laporte \& Consolini, 1991) which may be activated in the case of an emergency and remain latent the rest of the time. Saleh et al. (2010) highlight these same dimensions by emphasizing a commitment to and consensus on production and safety as concomitant organizational goals. However, some authors underline that HRO principals also give rise to some difficulties, in particular in the case of situations with complexity, time pressure and risk of irreversibility. Firstly, in general terms, a too strong formal organizational structure might reduce the ability of organizational flexibility (van der Vegt, et al., 2015). Rules cannot precisely prescribe behavior in all kinds of situations (Eberl, et al., 2015) and the "safety culture" is confronted 
with the complexity of the system and the limits of the actors' capacities (Laporte \& Consolini, 1991).

Moreover, rules may contradict each other. If we take an example from the same field studied by Roberts et al. (1994), a commander at the head of a Naval Force composed of aircraft and surface vessels has to choose between which rules to put forward: the rules focusing on discreet protection (concerning the organization of the vessels protecting submarines) or giving priority to Air Fight rules but without discreet protection. In situations where time pressure is a factor, there is no real time to deliberate. These types of contradictions coming from complexity have been raised, for instance, by Brehmer (1992) who highlights that tasks "are complex in the sense that they require the subjects to consider many different elements, e.g., many different and possibly conflicting goals".

Lastly, it may also be impossible with time pressure, to follow all the rules (Davis, et al., 2009), which raises the question of their prioritization.

So, the difficulties, for a decision-maker, when faced with a new situation when he/she has to act quickly - considering that in case of error there is a risk of irreversible damages - rely on being able to solve conflicts between rules and to (re)prioritize a set of rules.

\subsubsection{Reliability from the sensemaking approach}

The essence of sensemaking is to provide an understanding of how meaning and artifacts are produced and reproduced collectively (Czarniawska-Joerges, 1992; Saleh, et al., 2010). Communication appears as a key component in this process (Weick, et al., 2005). It "involves turning circumstances into a situation that is comprehended explicitly in words and that serves as a springboard into action" (Weick, et al., 2005). In practice, actors are constantly engaging in sensemaking of their environments in high-complexity and high-turbulence environments (Boudes \& Laroche, 2009; Brown, 2004). In these situations, the ability "in shifting from 
centralized authority during routine operations to local/decentralized authority for hazardous situations" (Saleh, et al., 2010) requires that these communications be integrated in an organizational culture centered on reliability. The latter allows for the creation of "a homogeneous set of assumptions and decision premises which, when they are invoked on a local and decentralized basis, preserve coordination and centralization" (Weick, 1987).

The quality of communication in an organizational culture of reliability is thus a necessary condition for organizational reliability (Kœnig, et al., 2016), especially when these organizations are confronted with contexts that combine, at the same time, an information overload with constant turbulence and increasing complexity (Weick, 1995).

However, in CTI situations, the sensemaking approach faces issues hardly to solve because of its core principles. Indeed, in CTI, the strong time constraints limit the sense of building efficiency in the interactions - sensemaking (Weick, 1995; Weick, 2001) - and a learning process by trial/error is not possible because of risks of critical irreversibility (Weick, 1987; Weick \& Sutcliffe, 2011). Moreover, as shown above, the strategies used to manage information overload (omission, tolerance to error, filtering, abstraction to part the information overload) do not suit in CTI situations, either because these strategies admit errors in the decision-making process or because they accept simplified considerations (Sutcliffe \& Weick, 2006). In CTI situations, decision-makers may face situations - complex from their point of view - with the risk of losing their reference points justifying the necessity to interact in order to have the same representation of the situation (Weick, 1993; Yami, et al., 2015).

So the topical issues are, for a decision-maker, how to quickly generate valid knowledge knowing that 1) deliberating requires time, 2) considering that CTI situations require rapid action and 3) in case of error, there is a risk of irreversible damages to the entity to manage. Thus, in CTI situations, both the sensemaking and the HRO approaches face difficulties that are difficult to resolve given the principles that characterize them. Table 1 summarizes these 
difficulties.

Table 1. Issues difficult to resolve in HRO and sensemaking approaches

\begin{tabular}{|l|l|}
\hline \multicolumn{2}{|c|}{ Issues to solve in the context of CTI situations for a decision-maker using the } \\
\hline \multicolumn{1}{|c|}{ HROs approach } & \\
\hline When a decision-maker is confronted with a new & - How to quickly generate valid knowledge knowing \\
situation and knowing that he/she has to act quickly & that \\
and that in case of error there is a risk of irreversible & 1) deliberating requires time \\
damages to the entity to steer, & 2) CTI situations require quick action, \\
- How to solve conflicts between rules in real time? & 3) in case of error, is there a risk of irreversible damage \\
- How to re prioritize a set of rules in real-time? & to the entity to steer? \\
& $\begin{array}{l}\text { - How in practice can a decision-maker manage a } \\
\text { situation of information overload knowing that }\end{array}$ \\
1) CTI situations require to quick action and \\
2) in case of error there is a risk of irreversible \\
damages for the entity to steer?
\end{tabular}

\subsection{Reliability from a meta rules perspective}

In CTI situations, the high risks of irreversibility and the demand to act quickly means that for decision-makers a key issue is to preserve the integrity of the controlled system, which is a necessary condition for achieving the objectives. We propose introducing the concept of meta rules in view of increased reliability.

The concept of meta rules has appeared in different research fields, such as education, business research and entrepreneurship (Fuller, et al., 2009). In the first approach, meta rules correspond to one form of meta-level knowledge; Davis (1980) defines them as rules governing a set of lower-level rules constituting a framework of rules for which the priorities might change. In CTI situations, the primary function of meta rules is to identify critical structural points that enable decision-makers to gain an overview of the managed entity (e.g., service, organization) in order to preserve its integrity (i.e., to maintain the vital functions of the system). The central 
issue is to avoid decision errors that might lead to a degradation of the system's capacity to achieve its objectives (Bradley, et al., 2001; Brady, 1987; Davis, 1980).

Thus, from a conceptual point of view, meta rules fundamentally concern the sustainability of the entity to manage. That is why rules and meta rules cannot be considered on the same level. In this setting, meta rules entail more than identifying a limited number of simple rules (Cazenave, 2003; Cox, 2005; Davis, 1980). With meta rules, it is possible to attain an overall view of a situation, allowing decision-makers to redefine their priorities if necessary and reallocate resources to ensure the integrity of the controlled system. When meta rules reflect a logic of preservation and of sustainability of the entity to steer, rules focus above all on solving the problem in the most efficient way.

In addition, meta rules must be differentiated from heuristics, as analyzed by Bingham and Eisenhardt (2011). For these authors, heuristics refer to specific problem contexts and focus on capturing opportunities in dynamic environments. Moreover, they occur with restricted information, which is not necessarily the case for meta rules. In contrast, meta rules should enable decision-makers to construct a big picture, with a good situation awareness ${ }^{1}$ (Endsley, 2001). They form an integrative framework that supports quick decision-making while limiting erroneous choices.

Thus, the concept of meta rules should allow rapid action - as a response to the constraint of "time stress" - by making reliable decisions - as a response to the constraint risk of "critical irreversibility" - in CTI situations.

\footnotetext{
${ }^{1}$ For Endsley (1995), situation awareness corresponds to the perception of the elements in the environment within a volume of time and space, the comprehension of their meaning and the projection of their status in the near future.
} 


\section{Analysis models and proposition}

\subsection{Reliability, rules and meta rules}

Our argument about the relationships between rules and meta rules is organized around three propositions.

Proposition 1: As already stated, a strict compliance with rules plays a central role in the reliability of High Reliability Organizations (Roberts \& Rousseau, 1989). Rules enable the decision-maker to decide quickly about issues which have already been covered. According to the HRO approach, the compliance with rules is a key factor of reliability leading us to formulate the following proposition:

P1: Complying with rules has a positive effect on the reliability level.

Proposition 2: The reliability level associated with proposition 1 can be improved by the use of meta rules. Indeed, in a real situation, the decision-maker does not face one but several problems. The issue "problem encountered/rule to be mobilized" must, therefore, be reevaluated quickly in view of the other problems that the decision-maker faces simultaneously. Thus, meta rules, because they enable the decision-maker to have a global intelligence of the entity being managed, are likely to play the role of a mediating variable between the rules and the reliability. These elements lead us to consider that the mobilization of a larger number of rules, due to the multiplicity of problems to solve, should imply for the decision-maker a more frequent use of meta rules. The use of meta rules should improve the reliability of decisionmaking. This leads us to formulate the following proposition:

P2: Meta rules play a mediating role between the rules and the reliability, which can be decomposed into two effects: (a) the mobilization of a more important number of rules - due to the multiplicity of problems to solve - is associated with a more important use of meta rules (first part of the mediating effect); (b) meta rules - because they make an overall understanding 
of the situation possible - have a positive effect on the reliability level (second part of the mediating effect).

Proposition 3: Situations with increasing complexity are, however, more difficult to solve for the decision-maker with rules-based behavior. Indeed, in these situations, the identification and the choice between the rules to follow take time, all the more so if the decision-maker does not know all the rules. He/she has to check the written documents in which the rules that apply for the situation are detailed. In an HRO context, the complexity of technologies requires that all procedures are precisely written (Roberts \& Rousseau, 1989). But reading these documents takes time, whereas the decision-maker is facing CTI situations constraints.

These elements lead us to consider that in situations with increasing complexity, the decisionmaker should mobilize fewer and fewer rules for a more important use of meta rules. Indeed, only meta rules enable the decision-maker to quickly identify the critical points on which he/she must act to ensure the integrity of the entity being managed. The use of meta rules being positively associated with reliability, this leads us to formulate the following proposition, complementary with the previous ones:

P3: In situations with increasing complexity, meta rules play a mediating role between the rules and the reliability, which can be decomposed into two effects: (a) less use of rules - due to increasing complexity - is associated with a more important use of meta rules (first part of the mediating effect of meta rules), (b) meta rules - that are concerned with preserving the integrity of the entity to be piloted - have a positive effect on the reliability level (second part of the mediating effect of meta rules). 
Figure 1 (Model 1) summarizes these first three propositions.

Figure 1. Reliability, rules, meta rules and complexity (Model 1):

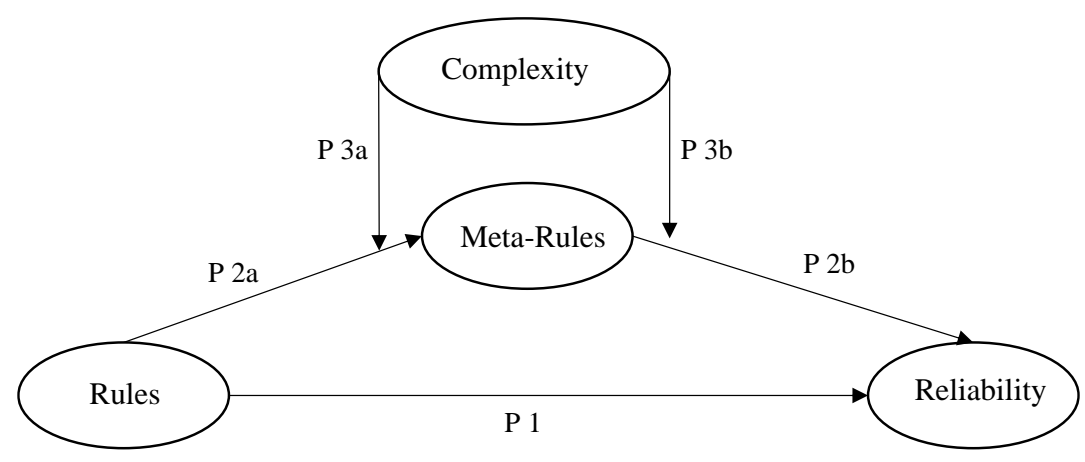

\subsection{Reliability, interactions and meta rules}

Our argument about the relationships between interactions and meta rules is organized, like previously, around three propositions.

Proposition 4: In unusual or unknown situations, the socio-constructionist approach of sense making (Weick, et al., 2005) considers the interactions as a means of generating new knowledge. The interactions enable the decision-maker to have an understanding of the situation. They avoid the strategies of "blind search" (Rasmussen, 1983) and can be a condition for organizational reliability (Weick, 1995). These elements lead us to propose the following proposition:

P4: Interactions positively affect reliability.

Proposition 5: The reliability level associated with proposition 4 can be improved by the use of meta rules. The difficulty with the knowledge produced by the interactions is that this knowledge is not necessarily "robust" (Artinger, et al., 2015; Maitland \& Sammartino, 2015). Some researchers go beyond this constraint and highlight that the use of simple rules or "frugal heuristics" (Artinger, et al., 2015; Goldstein \& Gigerenzer, 2009) can be a rational strategy 
(Bingham \& Eisenhardt, 2011). They enable a degree of plasticity - the ability to improvise (Davis, et al., 2009) while providing a framework that "keeps behaviors at least partially coherent" (Bingham \& Eisenhardt, 2011). However, as noted before, CTI situations require not only rapid action but also no error in the decision-making (Faraj \& Xiao, 2006; Roberts, 1990) due to risks of critical irreversibility.

These elements lead us to consider that, in CTI situations, the mobilization of meta rules by the decision-maker should enable him/her to analyze rapidly whether what is produced by interactions in the sensemaking process is suitable or not. Indeed, meta rules allow for a rapidly global understanding of the sensitive points for the entity to manage and make certain that relevant decisions to maintain the integrity of the entity to drive are taken. Thus, the relationship between interactions and the use of meta rules should be positive and the use of these meta rules should positively affect reliability. These elements lead us to propose the following proposition: P5: Meta rules play a mediating role between interactions and reliability, which are composed of two effects: (a) the important mobilization of interactions, due to the multiplicity of problems to solve, is associated with a greater use of meta rules (first part of the mediating effect), (b) the meta rules, as noted, have a positive effect on level of reliability (second part of the mediating effect).

Proposition 6: However, in situations with increasing complexity, it becomes more difficult for the decision-maker to interact with his/her teammates. Indeed, in these situations, the deliberation process requires more and more time to gain intelligence of the situation, which is hardly compatible with the constraints of CTI situations. As Rasmussen (1983) points out about human capabilities and knowledge-based behaviors, "only a few elements of a problem can be within the span of attention simultaneously. This means that the complex net of causal relations of an environment must be treated in a chain of mental operations". 
These elements lead us to consider that in CTI situations with increasing complexity there is no simple linear relation between the multiplicity of interactions and the producted sense; more (fewer) interactions do not produce more (less) sense. One way to unravel this "limit of human capabilities" (Rasmussen, 1983) is to change the level of abstraction. In a situation of increasing complexity, it is not so much a question of resorting to more interactions than to mobilizing meta rules. The mobilization of the latter remains, however, without simple linear relations with the level of interactions. These remarks lead us to formulate the following proposition:

P6: The incidence of level of increasing complexity on the mediating effect of meta rules between the interactions and reliability is not the same depending on the part of this mediating effect; (a): due to the limits of human cognitive capabilities, there is no simple linear relationship - positive or negative - between the interactions and the meta rules as the level of complexity increases. In other words, more complexity does not necessarily involve more interactions in its relationship with meta rules (first part of the mediating effect of meta rules); (b): in increasing complexity, the use of meta rules - as explained previously - has a positive effect on level of reliability (second part of the mediating effect of meta rules).

Figure 2 (Model 2) summarizes these last three propositions.

Figure 2. Reliability, interactions, meta rules and complexity (Model 2):

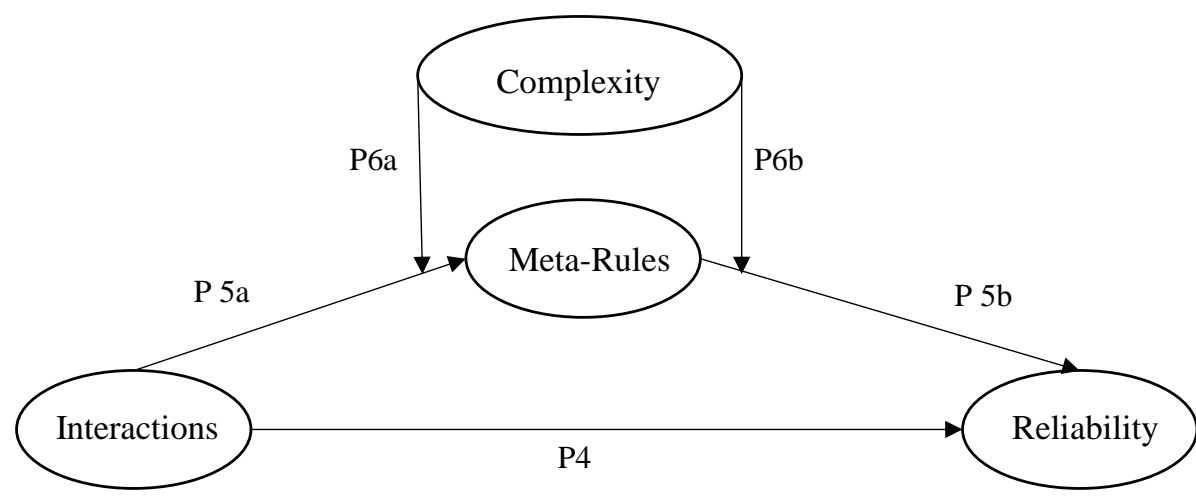




\subsection{Reliability and comparison « rules » vs « interactions »}

Proposition 7: Finally, we propose comparing the explanatory power of the HRO and sensemaking approaches.

By taking into account the specificities of CTI situations, which make the learning process by trial/error impossible due to emergency constraints and irreversible decisions in case of error, the association of rules - identified as the source of reliability (Weick, 1993) - with the flexibility in real-time of decision-making by the use of meta rules, should allow for obtaining a higher level of reliability. In other words, the association of the HRO approach with meta rules should have, in the specific case of CTI situations, a better explanatory power than the explanatory power coming from the association of meta rules with interactions.

Hence, we further formulated the following proposal:

P7: The overall reliability level is higher with the HRO approach (Model 1) than with the sensemaking approach (Model 2).

\section{Method}

\subsection{Field of study}

To test our propositions, we chose the French Navy corresponding to the features of HRO, (Roberts, et al., 1994) and specifically, the French Naval Academy. The Naval Academy trains French Navy career officers whose responsibilities include guiding and commanding operational units (combat vessels, submarines, naval aviation fleets, Navy commandos). During their training at the Naval Academy, officers develop the skills that will make them the future leaders of the Navy. The theoretical and practical training takes place over six semesters and focuses on three fundamental areas: maritime training, humanities and military training and scientific training. After graduation from the Academy, career officers will occupy different positions, depending on their chosen training, whether in operations (e.g., underwater warfare, 
surface warfare, naval aviation, commando) or operational support (e.g., propulsion, aeronautical and nuclear energy). Later in their careers, officers often take more strategic and prospective roles and occupy positions in the general staff, planning, expert roles or piloting in the fields of operations, weaponry, intelligence or human resources. They may command one or several operational units (e.g., commando, aircraft fleet, frigate, submarine, naval base). Of the three fundamental training areas, maritime training involves the progressive acquisition of seamanship, knowledge and practice maneuvering and navigating, as well as an understanding of the propulsion and energy production systems used on board ships. This training provides cadets with the skills necessary to perform the roles of an officer of the watch, operations officer of the watch or engineering officer of the watch. Their education is provided by professional sailors. Regular trips, several weeks in length, are scheduled throughout the instructional program, and the cadets' skills are tested during a long-term mission at sea in their sixth semester. The practical application takes place on instructional ships (traditional and racing sailboats, motor boats, training ships) and with a navigation simulator recreating a full-scale navigational bridge at scale 1 surrounded by $360^{\circ}$ screens depicting a maritime environment.

\subsection{Sample design}

The Naval Academy simulator consists of four bridges and a command post that allows users to practice various navigation situations based on scenarios. The primary goal of the simulator is to provide students with the basic skills of an officer of the watch on board a ship before they navigate the actual training ship. This simulator also can monitor cadets' reactions to complex or dangerous situations in a virtual environment. Therefore, we selected this simulator for this study. To create the scenario set up on the simulator, we used a database corresponding to accidents that occurred during real nautical situations on board Navy vessels. After analyzing this database, we retained the situations in which the conditions of complexity, urgency and 
human errors led to irreversible damages (death) in order to work on CTI situation criterias. We used the features of these critical situations to transform them into scenarios on the simulator: one scenario per team of three cadets based on the same kind of constraints: the proximity to danger, problems of visibility, technical problems. The small differences in scenarios per team came from the order in which constraints appeared, the geographical location (Brest Harbour or Lorient Harbour). Each scenario proposed to cadets relied on the same basis. The scenario reflected real nautical events and particularly complex situations with critical points such as:

$>$ a navigation situation (a moving boat)

$>$ a low level of visibility

the emergence of a new element in a short period of time (other boats, fire)

dangers close by (rocks, coast, floating buoy).

The conditions of complexity came from the necessity to manage different new elements and the rules associated with them, whilst taking into account the nearby dangers and the rules that must be followed to deal with them. The conditions of time pressure were due to the short period of time available to manage all these parameters. In such conditions, a situation becomes increasingly complex due to the sequence of problems to solve in a short period of time (Halford, et al., 1998). And lastly, the conditions of error irreversibility came from the severe consequences to the vessel (damages to the boat hull, to its equipment and even to crew members) with possible effects on the integrity of the system and its sustainability. To illustrate this work in Table 2, we present the scenario "Arrival at Lorient Harbour " that six different teams had to manage:

Table 2. Scenario "Arrival at Lorient Harbour". 


\begin{tabular}{|c|c|c|c|}
\hline & \multicolumn{3}{|c|}{ Scenario: Arrival at Lorient Harbour - Example of six teams } \\
\hline & Team 1 on bridge $A$ & Team 2 on bridge $B$ & Team 3 on bridge $\mathrm{C}$ \\
\hline $\begin{array}{l}1^{\text {st }} \\
120^{\prime} \\
\text { session }\end{array}$ & $\begin{array}{l}\text { Bridge A } \\
\text { 9h47: } 1 \text { inflatable boat right } \\
\text { in front of the ship + } 1 \\
\text { tugboat } \\
\text { 9h52: } 1 \text { interruption by a } \\
\text { phone contact from Lorient } \\
\text { Harbour } \\
\text { 9h52: } 1 \text { tugboat } \\
\text { 9h58: } 1 \text { sailboat + marking } \\
\text { buoy to avoid }\end{array}$ & $\begin{array}{l}\text { Bridge B } \\
\text { 9h38: } 1 \text { marking buoy to } \\
\text { avoid } \\
\text { 9h39: } 1 \text { tugboat very close on } \\
\text { the starboard side } \\
\text { 9h42: } 1 \text { training ship } \\
\text { 9h43: } 1 \text { interruption by a } \\
\text { phone contact from Lorient } \\
\text { Harbour } \\
\text { 9h44: } 1 \text { inflatable boat }\end{array}$ & $\begin{array}{l}\text { Bridge C } \\
\text { 9h22: } 1 \text { tugboat }+1 \text { floating } \\
\text { tree trunk } \\
\text { 9h29: interruption by a phone } \\
\text { contact from Lorient Harbour } \\
\text { (question: which docking } \\
\text { ring do you want?) } \\
\text { 9h29: } 1 \text { inflatable boat } \\
\text { 9h31: } 1 \text { inflatable boat } \\
\text { 9h30: } 2^{\text {nd }} \text { training ship }\end{array}$ \\
\hline & Team 4 on bridge $\mathrm{A}$ & Team 5 on bridge $\mathrm{B}$ & Team 6 on bridge $\mathrm{C}$ \\
\hline $\begin{array}{l}2^{\text {nd }} \\
120 \\
\text { session }\end{array}$ & $\begin{array}{l}\text { 11h25: } 1 \text { fishing trawler } \\
\text { 11h25: } 1 \text { gyro breakdown } \\
\text { 11h27: } 1 \text { man overboard } \\
\text { 11h28: } 1 \text { VIP on the bridge }\end{array}$ & $\begin{array}{l}\text { 11h25: } 1 \text { military ship \& } 1 \\
\text { fishing trawler } \\
\text { 11h26: } 1 \text { interruption } \\
\text { 11h27: } 1 \text { break down \& } 1 \\
\text { boat } \\
\text { 11h28: } 1 \text { water leak }\end{array}$ & $\begin{array}{l}\text { 11h41: } 1 \text { military ship } \\
\text { 11h43: } 1 \text { gyro breakdown at } \\
5^{\circ}+1 \text { boat on the port side } \\
\text { and } 2 \text { marking buoys } \\
\text { 11h4: a journalist and a VIP } \\
\text { on the bridge } \\
\text { 11h53: } 1 \text { gyro breakdown }+1 \\
\text { boat on the port side } \\
\text { 11h56: gyro OK } \\
\text { 11h58: } 1 \text { inflatable boat on } \\
\text { the starboard side }\end{array}$ \\
\hline
\end{tabular}

\subsection{Data collection}

As previously explained, the simulator was used as research equipment to implement the nautical scenario: the observations of team behaviours were made during the implementation of the scenario and collected in a questionnaire filled out by nautical experts on the bridge simulator (French Naval academy instructors).

Our sample was made up of 108 bridge teams of three cadets each playing three different roles, namely the leader (F1), the deputy officer of the watch (F2) and the watchkeeper (F3). Given the constraints of the number of cadets at the French Naval Academy - only 274 cadets are trained each year - some of them played several team member roles on several teams. 
Each team had a nautical mission on a simulator bridge (place unit) during $120 \mathrm{mn}$ (time unit) with a period of variability (with complexity, time pressure, risks of error) from 5 to $10 \mathrm{mn}$. These CTI situations were created from a command control room. Indeed, both the inputs and events came from a central command room. The observations made from the teams' behaviours during the scenario implementation was collected on a questionnaire filled out by experts (instructors) - the simulator being used to implement the nautical scenario.

All data was collected in a questionnaire made specifically for this test and filled out by nautical experts on the bridge (French Naval academy instructors). For each bridge team, one expert completed a questionnaire, so the number of questionnaires corresponded to the number of teams (108). We tested this questionnaire in advance, with a verbal protocol method and a focus group with 10 experts (i.e., instructors assessing cadets on the simulator). The observations were done by instructors (nautical experts) who completed the questionnaire and stayed on the bridge during the exercise.

During these two-hour periods of navigation, technicians working in the central command room inserted periods of variability from 5 to 10 minutes corresponding to unexpected situations with a series of events based on real nautical situations recreating a complex, urgent situation with risks of severe damage in order to create CTI conditions. Indeed, each scenario contained a 5 to $10 \mathrm{mn}$-period whose complexity appeared through the introduction of multiple incidents, difficult sea conditions and time pressure. The details of our work on the simulator came from Journé’s work (Journé, 1999; Journé \& Raulet-Croset, 2008).

The questionnaire allowed the 10 instructors to identify the compliance with rules, the level of interactions between the three team members and the use of meta rules. The objective was to identify the associations of variables that allow teams to achieve the highest level of reliability. 


\subsection{Variables}

Our observations focused on five variables: Compliance with Rules, Interactions, use of Meta rules, Reliability level and Complexity level.

Our propositions are based on the association of these variables. In this section, we explain how we operationalized each of these variables with measurement scales. The specific measurement scales, developed for this work, are based on prior literature, experts' analyses and semistructured interviews with French Navy instructors.

Independent Variables:

- Compliance with Rules

Romelaer (1998) defines a formal rule as a regularity of behavior that is used as a formalized standard expressed with items. The works of Crozier and Friedberg (1977) or Weick (1998) emphasize the possible behaviors of actors regarding compliance with rules: actors can respect them, respect them while maintaining a margin for maneuver, deviate from them by improvising.

Measurement scales on procedures are uncommon. Bunn's work (1994) on the measurement of procedural control based on 10 items on a seven-point Likert scale focuses more on the relevance of procedures than on their use. They seem to be less adapted to our research objective, so we proposed the measurement of the variable "Rules," taking into account the specificity of the field of study.

Indeed, Compliance with Rules is formally written in the document, General Guidelines for Boating Safety, written in 2012. These rules correspond to the detailed rules of nautical safety, which are available for crews on "clipboards" on the bridge. They are included in a list of rules to be applied for each type of nautical situation. Therefore, expert assessors can determine if the rules have been strictly respected or if any kind of deviation has occurred. 
We, therefore, proposed that the "Rules" variable be measured from a one-dimensional scale relative to the compliance with rules by the bridge team members. The rule-based actions are specified by each rule (Davis, et al., 2009). To explain the differences between rules and meta rules, we give illustrations from our studied field; rules represent rules written on a clipboard available on the bridge for bridge teams. These rules are written and give details for taking specific action in a type of situation (for example, rules for "man overboard", including a sequence of orders to strictly respect described in Table 3).

Table 3. Rules to follow for a man overboard situation.

\begin{tabular}{|l|l|}
\hline \multicolumn{2}{|l|}{ Function for the leader F1 } \\
\hline $1 /$ & Identify the location of the man overboard on GPS (button MARK/MOB) \\
\hline $2 /$ & Warn the ship crew by pressing the horn 4 times and saying, "a man overboard at X location, the teams \\
& responsible for rescue boat at your position. This is not an exercise." \\
\hline $3 /$ & Begin the maneuver corresponding to the plan. \\
\hline $4 /$ & "Operator's maneuver in the machine room for man overboard rule" \\
\hline $5 /$ & Communications VHF on P3 (mobile VHF) for the rescue boat and for the bridge switched on and \\
tested \\
\hline $6 /$ & The rescue boat is prepared for action \\
\hline $7 /$ & Stop the fire pump \\
\hline C/ & Give the order "launch the rescue boat " \\
\hline
\end{tabular}

Thus, for a warship, we measured the compliance with rules by using a one-dimensional scale with three items, measured on a five-point Likert scale that indicates each actor's compliance with the rules in the nautical situation. Instructors are expert assessors, they can determine if the rules have been strictly respected. The measurement of the variable Rules is specified in APPENDIX 1. 
- Interactions

We justified the choice of the variable "Interactions" because this variable is one of the four sources of resilience identified by Weick (1993). Moreover, the importance of this variable also emerges from the results of our quantitative study based on the analysis of accidents (Navy database) underlining that lack of communication constitutes a major source of errors.

We note that Weick (1993), when he identifies "respectful interactions" as a source of resilience, gives it a larger meaning; we focused on the verbal aspect of interactions.

We measured the variable "Interactions" from the verbal interactions between the members of the bridge team (between F1 and deputy officer F2, between F1 and the other members of the team, i.e., F3, between F2 to F3) thanks to a questionnaire constructed to collect the measures of this variable. The measurement of the variable Interactions is specified in APPENDIX 1.

Mediating variable

\section{- Meta rules}

Meta rules enable actors to prioritize some of the rules and, therefore, arbitrate among them (Davis, et al., 1977). These meta rules enable actors to gain an abstract overview of the system and thus quickly diagnose its level of control. For our investigation, the item "applying rules of a general level" and "applying rules of a higher level" corresponded to five meta rules of general navigation principles, as presented at the conference on the General Guidelines for Conduct At Sea (DG NAUT, latest version July 2012) [Directives Générales pour la Conduite Nautique (DG NAUT)] and summarized in Table 4.

We differentiated these meta rules from rules. If rule-based actions are specified by each rule (Davis, et al., 2009), meta rules are not specific to one type of action in a situation. Davis (1980) defines meta rules as rules governing a set of lower-level rules, corresponding to one form of meta-level knowledge. That is why "to call for watchfulness", "to reduce one's speed", "to 
take visual cues in the environment", "to request an exemption from the captain for one action (not provided by rules)", and "to report to the captain changes in the nautical situation" (in order to request an exemption) have been identified by experts (10 instructors in a focus group) as meta rules; they correspond to global measures of rules and enable the decision-maker (the leader of the bridge team) crew to take, the first time, measures suitable for any kind of nautical situations (corresponding to the features of meta rules) in order to preserve the integrity of the system and its capacity to carry out the mission and make it possible, the second time, to respect detailed rules covered for specific situations. The meta rules described in the following Table 4 were identified as meta rules by experts because for any kind of situation they enable the crew members to create a framework for actions to preserve the integrity of the ship.

Table 4. Meta rules for the officer on watch.

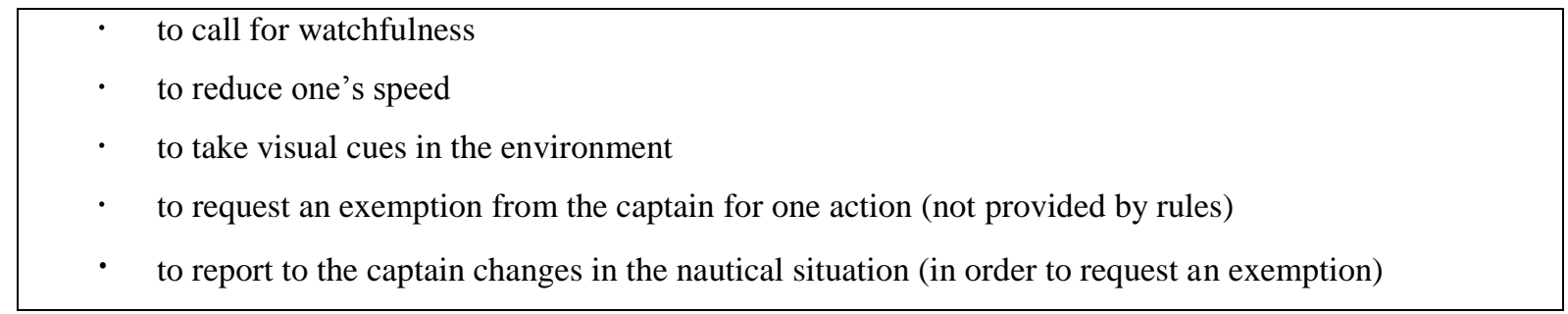
We chose the meta rules resulting from the focus group as measurement criteria for this variable. The measurement of the variable Meta rules is specified in APPENDIX 1.

\section{Dependent variable}

\section{- Reliability}

There is no consensus about the best measure of the reliability of a system. Prior literature refers to performance criteria as often as it does to system errors. In addition, the HRO literature studies their singular performance characterized by a low rate of catastrophe (Roberts \& Rousseau, 1989; Roberts, et al., 1994). Therefore, we chose to measure reliability as the impact of errors on the integrity of the system (Roberts, et al., 1994). 
Moreover, navigating a ship involves a system composed of people, equipment and the vessel. Semi-structured interviews with experts highlighted the links between technical and human reliability; for a bridge team, it entails its ability to carry out its mission, even in a deteriorating situation. APPENDIX 1 presents the measurements of the Reliability variable.

Moderating variable

\section{- Complexity}

The level of complexity was the fifth element that we wanted to evaluate. Complexity has been studied widely (Cf. particularly 1999; Burnes, 2005; McKelvey, 1997; McKelvey, 1999; Sterman, 1994). In line with Boisot and McKelvey's (2010) analysis, we consider that a complexity threshold has been reached when the number of interacting elements increases and when the increasing amount of feedback moves the system away from an orderly state. Accordingly, in CTI situations, it is possible to measure complexity as the emergence of unexpected, unusual events in a given area and within a limited time frame, such that these events may interact. When they do so, beyond a certain threshold that varies with the competences of the actors in the situation, they may shift the system from an orderly state into a complex one (Boisot \& McKelvey, 2010 op.cit 421).

Thus, we measured the Complexity variable through the level of time pressure and constraints in the situations to manage. For our study, the bridge teams had to manage a situation of proximity navigation, with reduced visibility and the need to react in a very short time to three or four unforeseen events. The item used to measure Complexity was "Please indicate the level of complexity of the situation (constraints, uncertainty, pressure) on a five-point Likert scale (1: very low, 5: very high). 


\section{Analyses and results}

\subsection{Statistical technique}

For this study, we used the technique of the structural equations model based on variances, Partial Least Square PLS. This method is appropriate because it has a number of advantages related to its better adaptation to exploratory research (Tenenhaus, et al., 2005), and it is a technique particularly suitable for incorporating composite constructs (Chin, 1998; Haenlein \& Kaplan, 2004). For this research, Rules and Meta rules variables were regarded as composite constructs, while Reliability and Interaction constructs were defined as factors. In order to analyze the mediating effect of the Meta rule variable moderated by Complexity, the methodology of analysis of indirect effects was applied (Zhao, et al., 2010). The version 2.12.2 of the macro PROCESS for IBMSPSS Statistics 20 (Hayes, 2017) was used to perform a posthoc conditional process analysis to examine whether the indirect effect of Rule construct on Reliability in Model 1 (Interactions on Reliability in Model 2) through Meta rule construct was conditioned/moderated by Complexity. The models we used to test the proposals are the following: Bootstrap analysis with 5000 subsamples for all the empirical analyses was carried out (Leal-Rodríguez, et al., 2014).

\subsection{Measure validation of the models}

We ensured the content validity of the constructs by adapting previously validated scales. Reliability and convergent validity of the reflective constructs (Reliability and Interactions) was evaluated as follows (Henseler, et al., 2016): Construct reliability by checking whether the construct composite reliability (Dijstra \& Henseler's rho $\left(\mathrm{p}_{\mathrm{A}}\right)$ ) and indicator loadings were above the threshold of 0.71 (Chin, 2010). Convergent validity was tested by examining whether the construct average variance extracted (AVE) was above the recommended value of 0.5 (Hair, et al., 2010) check for the reflective construct discriminant validity in Model 2 by analyzing 
whether the square root of the construct AVE was vertical and horizontally greater than its correlation with other constructs (Gefen, et al., 2000).

Composite constructs (Rule and Meta rule constructs) should be assessed differently than reflective constructs, since traditional assessments of reliability and validity do not apply well to formative constructs (Petter, et al., 2007). Multi-collinearity, weights and their level of significance have to be checked (Benitez \& Ray, 2012; Cenfetelli, et al., 2009). We checked for multicollinearity by estimating the variance inflation factor (VIF) for the three indicators of Rules, three indicators of Interactions construct and four indicators of Meta rules. All these VIF values were lower than 10 , thus suggesting that multicollinearity was not a problem in our data (Petter, et al., 2007). Only one item linked to Meta rule construct had a non-significant positive weight of 0.236 (Model 1) and 0.033 (Model 2). As the factor loadings were significant and contributed highly to the Meta rule concept, we decided to keep it (Benitez, et al., 2017). Overall, this analysis suggested good properties for all the constructs (APPENDIX 1).

\subsection{Results}

Results for Model 1 (Table 5) show that Rules have a positive and very significant relationship with Reliability (beta: 0.744 , t-value: 11.272 ). This result supports P1. Model 1 also reveals that Rules have a positive and significant relationship with Meta rules (beta: 0.587, t-value: 9.074), which in turn enable the team to improve Reliability (beta: 0.145 , $\mathrm{t}$-value: 2.066 ).

Table 5. Structural model evaluation: Model 1 rule, meta rule and reliability:

\begin{tabular}{|l|c|}
\hline Model 1 & Beta (t-test, p-value) \\
\hline Rule $\rightarrow$ Reliability & $0.744(11.272 ; 0.000)$ \\
\hline Rule $\rightarrow$ Meta rule & $0.587(9.074 ; 0.000)$ \\
\hline Meta rule $\rightarrow$ Reliability & $0.145(2.066 ; 0.019)$ \\
\hline Complexity $\rightarrow$ Meta rule & $0.200(2.543 ; 0.06)$ \\
\hline
\end{tabular}




\begin{tabular}{|l|c|}
\hline Complexity $\rightarrow$ Reliability & $0.072(1.440 ; 0.075)$ \\
\hline Complexity Rule $\rightarrow$ Meta rule & $-0.072(1.580 ; 0.057)$ \\
\hline Complexity Meta rule $\rightarrow$ Reliability & $0.067(1.448 ; 0.074)$ \\
\hline Indirect effects & $0.085(1.787 ; 0.037)$ \\
\hline Rule-reliability through meta rule & {$[0.017-0.174]$} \\
\hline Confidence Intervals & \\
\hline
\end{tabular}

Note: t-values are presented in parentheses. Confidence intervals are presented in brackets. Adjusted $\mathrm{R}^{2}$ (Meta rule: 0.403; Reliability: 0.739). SRMR: 0.058 .

Post-hoc conditional process analysis. Indirect effect of rule over reliability through meta rule conditioned to complexity

\begin{tabular}{|l|c|c|c|}
\hline Complexity & $\begin{array}{c}\text { Indirect } \\
\text { effects }\end{array}$ & Boot Standard error & Confidence intervals \\
\hline-1.468 & 0.040 & 0.065 & {$[-0.046-0.215]$} \\
\hline-0.404 & 0.075 & 0.048 & {$[0.001-0.184]$} \\
\hline-0.404 & 0.075 & 0.048 & {$[0.001-0.184]$} \\
\hline 0.660 & 0.111 & 0.051 & {$[0.021-0.217]$} \\
\hline 1.724 & 0.147 & 0.079 & {$[0.019-0.329]$} \\
\hline
\end{tabular}

Values for complexity are $10^{\text {th }}, 25^{\text {th }}, 50^{\text {th }}, 75^{\text {th }}$, and $90^{\text {th }}$ percentiles. Level of confidence for all confidence intervals 95. Level of confidence for all confidence intervals 95

The indirect effect of Rules over Reliability by means of Meta rules was tested considering the methodology of indirect effects analysis proposed by Zhao et al. (2010). Therefore, we developed a complementary mediation analysis by performing a bootstrap confidence interval test which enabled us to measure the total and specific indirect effects of the intermediate variable included in Model 1 (Preacher \& Hayes, 2004). The results show the indirect effect of Rules on Reliability is significant. This is the reason why it is evident that this effect was mediated by the Meta rules construct, which supports $\mathrm{P} 2$.

But the question to answer is whether this indirect effect differs depending on the complexity of a situation. The interaction effect between Rule and Complexity had a negative relationship with Meta rules (beta: -0.072 , t-value: 1.440 ), while the interaction effect between Meta rules and Complexity had a positive relationship with Reliability (beta: 0.067, t-value: 1.448). 
Overall, Complexity moderated the indirect effect of Rule on Reliability through Meta rule as shown by the post-hoc conditional process analysis to examine whether the indirect effect of Rule on Reliability through Meta rule was moderated by Complexity. We estimated the conditional indirect effects and the bias corrected $95 \%$ bootstrap confidence intervals for the indirect effects at various values of Complexity. A confidence interval not including zero means that the indirect effect of Rule is significant at a specific value of Complexity. Complexity was estimated as the 10th, 25th, 50th, 75th and 90th percentiles of the distribution in the sample (Leal-Rodríguez, et al., 2014). Consequently, this result suggests that Rule affects Reliability by means of Meta rule, and that this indirect effect is stronger when the Complexity is high (P3).

Table 6 shows the results obtained for Model 2.

Table 6. Structural model evaluation: Model 2 Interactions, meta rule and reliability:

\begin{tabular}{|c|c|c|c|}
\hline Model 2 & \multicolumn{3}{|c|}{ Beta (t-value } \\
\hline Interactions $\rightarrow$ Reliability & \multicolumn{3}{|c|}{$0.514(5.889)$} \\
\hline Interactions $\rightarrow$ Meta rule & \multicolumn{3}{|c|}{$0.544(7.301)$} \\
\hline Meta rule $\rightarrow$ Reliability & \multicolumn{3}{|c|}{$0.332(3.629)$} \\
\hline Complexity $\rightarrow$ Meta rule & \multicolumn{3}{|c|}{$0.157(1.693)$} \\
\hline Complexity $\rightarrow$ Reliability & \multicolumn{3}{|c|}{$0.069(1.300)$} \\
\hline Complexity Interactions $\rightarrow$ Meta rule & \multicolumn{3}{|c|}{$-0.035(0.560)$} \\
\hline Complexity Meta rule $\rightarrow$ Reliability & \multicolumn{3}{|c|}{$0.077(1.496)$} \\
\hline \multicolumn{4}{|c|}{$\begin{array}{l}\text { Note: t-values are presented in parentheses. Confidence intervals are presented in brackets. Adjusted } \mathrm{R}^{2} \text { (Meta } \\
\text { rule: } 0.325 \text {; Reliability: } 0.595) \text {. SRMR: } 0.071 \text {. }\end{array}$} \\
\hline \multicolumn{4}{|l|}{ Indirect effects } \\
\hline $\begin{array}{l}\text { Interaction-reliability through meta rule } \\
\text { Confidence Intervals }\end{array}$ & \multicolumn{3}{|c|}{$0.181(2.729)$} \\
\hline \multicolumn{4}{|c|}{$\begin{array}{l}\text { Post-hoc conditional process analysis. Indirect effect of interaction variable over reliability through meta rule } \\
\text { conditioned to complexity }\end{array}$} \\
\hline Complexity & $\begin{array}{l}\text { Indirect } \\
\text { effects }\end{array}$ & $\begin{array}{l}\text { Boot Standard } \\
\quad \text { error }\end{array}$ & Confidence intervals \\
\hline-1.468 & 0.133 & 0.115 & {$[-0.004-0.442]$} \\
\hline
\end{tabular}




\begin{tabular}{|l|c|c|c|}
\hline-0.404 & 0.169 & 0.079 & {$[0.059-0.352]$} \\
\hline-0.404 & 0.169 & 0.079 & {$[0.059-0.352]$} \\
\hline 0.660 & 0.207 & 0.069 & {$[0.081-0.348]$} \\
\hline 1.724 & 0.244 & 0.118 & {$[0.070-0.541]$} \\
\hline $\begin{array}{l}\text { Values for complexity are } 10^{\text {th }}, 25^{\text {th }}, 50^{\text {th }}, 75^{\text {th }}, \text { and } 90^{\text {th }} \text { percentiles. Level of confidence for all confidence } \\
\text { intervals } 95 . \text { Level of confidence for all confidence intervals } 95 .\end{array}$ \\
\hline
\end{tabular}

The estimates reveal that the Interactions construct had a positive relationship with Reliability (beta: 0.514, t-value: 5.889), verifying P4. The model also discloses that Interactions had a positive and significant relationship with Meta rule (beta: 0.544, t-value: 7.301), which in turn allowed the team to improve Reliability (beta: 0.332, t-value: 3.629). In this model, the indirect effect of Interactions construct on Reliability through Meta rule was also verified (beta: 0.181 , t-value: 2.729). Therefore, Meta rule mediates the effect of the Interactions construct on Reliability and increases it, which supports P5. This indirect effect was moderated by the complexity level as the interaction effect between Meta rule and Complexity affects Reliability (beta: 0.077 , t-value: 1.496). The interaction effect between the Interactions construct and Complexity did not affect Meta rule (beta: -0.035 , t-value: 0.560 ). This result was reinforced in the post-hoc process analysis, as the confidence intervals for the indirect effect when Complexity increases did not include the value 0 . At low level of complexity, this variable did not affect the indirect effect of Interactions on Reliability, but when complexity was 0.660 the confidence interval did not include 0 [0.081-0.348], so the indirect effect was conditioned by the level of Complexity. Consequently, P6 can be verified because there is evidence to support a moderated effect of Complexity on the relationship between Meta rule and Reliability but not on the relationship between Interaction and Meta rule.

When comparing the $\mathrm{R}^{2}$ for Model 1 and Model 2, clearly the HRO approach shows a higher capacity to predict Reliability (Adjusted $\mathrm{R}^{2}: 73.9 \%$ ) than the sensemaking approach (adjusted $\left.\mathrm{R}^{2}: 59.5 \%\right)$. This result supports $\mathrm{P} 7$. 
Table 7 summarizes the results.

Table 7. Propositions summary and results:

\begin{tabular}{|c|c|}
\hline Propositions & Results \\
\hline $\begin{array}{l}\text { P1: Complying with rules has a positive effect on the } \\
\text { reliability level. }\end{array}$ & Supported \\
\hline $\begin{array}{l}\text { P2: Meta rules play a mediating role between the rules } \\
\text { and the reliability, which can be decomposed into two } \\
\text { effects: (a) the mobilization of a more important } \\
\text { number of rules - due to the multiplicity of problems } \\
\text { to solve - is associated with a more important use of } \\
\text { meta rules (first part of the mediating effect); (b) meta } \\
\text { rules - because they make an overall understanding of } \\
\text { the situation possible - have a positive effect on the } \\
\text { reliability level (second part of the mediating effect). }\end{array}$ & Supported \\
\hline $\begin{array}{l}\text { P3: In situations with increasing complexity, meta } \\
\text { rules play a mediating role between the rules and the } \\
\text { reliability, which can be decomposed into two effects: } \\
\text { (a) less use of rules - due to increasing complexity - is } \\
\text { associated with a more important use of meta rules } \\
\text { (first part of the mediating effect of meta rules), (b) } \\
\text { meta rules - that are concerned with preserving the } \\
\text { integrity of the entity to be piloted - have a positive } \\
\text { effect on the reliability level (second part of the } \\
\text { mediating effect of meta rules). }\end{array}$ & $\begin{array}{l}\text { Supported: complexity moderates the relationship } \\
\text { between Rule and Meta rule, but with a negative } \\
\text { coefficient (a) however the total indirect effect is } \\
\text { affected by complexity as it affects relationship } \\
\text { between Meta rule and Reliability in a very positive } \\
\text { way (b) }\end{array}$ \\
\hline P4: Interactions positively affect reliability & Supported \\
\hline $\begin{array}{l}\text { P5: Meta rules play a mediating role between } \\
\text { interactions and reliability which are composed of two } \\
\text { effects: (a) the important mobilization of interactions, } \\
\text { due to the multiplicity of problems to solve, is } \\
\text { associated with a greater use of meta rules (first part } \\
\text { of the mediating effect), (b) the meta rules, as noted, } \\
\text { have a positive effect on level of reliability (second } \\
\text { part of the mediating effect). }\end{array}$ & Supported \\
\hline $\begin{array}{l}\text { P6: The incidence of level of increasing complexity on } \\
\text { the mediating effect of meta rules between the } \\
\text { interactions and reliability is not the same depending } \\
\text { on the part of this mediating effect. (a): due to the } \\
\text { limits of human cognitive capabilities, there is no } \\
\text { simple linear relationship - positive or negative - }\end{array}$ & $\begin{array}{l}\text { Supported: Complexity does not moderate the } \\
\text { relationship between Interactions and Meta rule (a) but } \\
\text { the total indirect effect is affected by complexity as it } \\
\text { affects relationship between Meta rule and Reliability } \\
\text { (b) }\end{array}$ \\
\hline
\end{tabular}




\begin{tabular}{|l|l|}
\hline $\begin{array}{l}\text { between the interactions and the meta rules as the level } \\
\text { of complexity increases. In other words, more }\end{array}$ & \\
complexity does not necessarily involve more & \\
interactions in its relationship with meta rules (first & \\
part of the mediating effect of meta rules). \\
(b): In increasing complexity, the use of meta rules - \\
as explained previously - has a positive effect on level \\
of reliability (second part of the mediating effect of \\
meta rules)
\end{tabular}

\section{Discussion}

The concept of meta rules presented in this paper should provide a better understanding of how the answers of decision-makers in CTI situations can be improved. Two models were built in order to study the use of meta rules for more reliability in organizations and their links with HRO and sensemaking approaches.

\section{Lessons from the "rules - meta rules" model}

Results for Model 1 (Table 5) show that compliance with rules has a positive and very significant relationship with reliability, underlining the relevance of the HRO approach. Results also show that compliance with rules affects reliability by means of meta rules, this indirect effect being stronger when the complexity is high. Indeed, in a situation of increasing complexity, the understanding of a situation requires more and more time. This constraint can be overcome by meta rules that can quickly replace the use of rules in a holistic vision of the entity being managed. These results underline the stake of meta rules when the level of complexity increases.

Moreover, results also teach us that the level of complexity moderates the relationship between compliance with rules and meta rules - with a negative coefficient - underlining a probable 
substitution process between rules and meta rules in favour of the latest when complexity is increased. In the same way, as expected with an increasing level of complexity, the indirect effect due to meta rules becomes stronger underlining the key role played by meta rules when level of complexity increases.

These results mean that when level of complexity is increasing, the actor in a situation should refer to meta rules if he/she faces difficulties (no time, rules conflict) in complying with rules. However it should be pointed out that the move from a register of actions mobilizing rules to a register of actions giving a higher priority to meta rules is not obvious. Indeed, on the one hand, the actors may not necessarily be aware of the meta rules and this is all the more so as people are trained first of all to respect and not to derogate from the rules, in particular in military institutions, the field of study of our article. On the other hand, when rules are multiple, especially in HRO, knowing them and applying them, especially in situations of increasing complexity, can gradually mobilize all the cognitive capacities of the decision-maker, thus leaving little space for the attention that he/she should continue to pay to the global vision of the entity piloting. Finally, even if decision-makers are aware of the need to change the action register by referring more to the meta rules, they risk being hampered in this change because they know that, by referring less to the rules, they will engage their personal responsibilities if a major and irreversible incident occurs.

In spite of these difficulties, the results lead us to think that referring to meta rules is a possible solution to helping individuals quickly and easily resolve potential conflicts between different rules and make possible a re hierarchisation of rules in real time. Above all, the results remind us that the respect for rules appears to be a better condition for obtaining a higher reliability level, according to the HRO approach. Moreover, the mediating role of meta rules between the rules and the reliability level is a key point that deserves to be deepened. 


\section{Lessons from the model interactions - meta rules model}

In this second model, results (Table 6) show that interactions have a positive effect on the reliability level, confirming also the relevance of the sensemaking approach. However, because of a greater risk of error, the reliability level with interactions is lower than the reliability level when relying solely on rules, underlining that the HRO approach enables actors to obtain a higher level of reliability compared with the sensemaking approach in CTI situations. Moreover, when the level of complexity increases, the overall mediating effect in Model 2 has a positive and significant effect on reliability, showing the relevance of the use of meta rules. These results lead us to think that, in Model 2, the mediating role of meta rules positively affects the level of reliability when the complexity increases.

These findings enable us to progress with understanding the issues inherent in the improvement of decision-making in CTI situations. First, they highlight that, in the focal study of CTI, the use of interactions is not sufficient to produce robust knowledge for high reliability, as suggested by Weick (1993). Second, the use of meta rules makes it possible to improve the level of reliability. Thus, by offering an integrating framework, it is possible with meta rules to reduce the time of deliberation, as well as the risks of information overload. Moreover, meta rules provide elements that answer the two issues met within the framework of the sensemaking approach (shown in Table 1). Lastly, results also show that the overall reliability level is higher with the HRO approach (Model 1) than with the sensemaking approach (Model 2), emphasizing that the best of these two options is to use rules with meta rules. These results underline the value of meta rules for the management of CTI situations.

\section{Conceptual and practical issues pertaining to meta rules}

For CTI situations, the use of meta rules is a relevant practice, considering the difficulty associated with addressing all the information related to a sequence of challenging problems in 
a short period of time, especially if the decision-maker is not an expert. In practice, finding a solution is difficult because the time needed to conduct an analysis exceeds the time available in the situation, which demands rapid decision-making.

Meta rules, therefore, make it possible to solve some issues with which the HRO and sensemaking approaches are confronted (cf. Table 1 in part II). Thus, with the HRO approach, meta rules - because they provide a global vision of the entity to be managed and points of vulnerability - allow a rapid response to potential conflicts between rules and the need or not to re-prioritize them. Similarly, with the sensemaking approach, meta rules allow the meaning produced by the interactions to be replaced with an overall vision of the entity to be managed. This rapid reassessment and this reframing of the meaning produced in the interaction limits, in CTI situations, the risks of information overload.

The usefulness of meta rules is not limited to CTI situations. Decision-making can be difficult in any situation that characterizes many rules and requires substantial knowledge to take action. Meta rules constitute a facilitator strategy, making it possible to return to the basics and using only the relevant rules. Fundamentally, they make sensemaking possible. Moreover, two main factors justify their ability to lead actors to make robust and reliable decisions: they facilitate the creation of both "a big picture" and a "situation awareness" (Endsley, 2001). Thus, meta rules enable decision-makers to stand back temporarily from the pre-established decomposition of tasks (i.e., compliance with rules) and focus on sensemaking. For the decision-maker, understanding the situation through meta rules, at a key time and up to its likely evolution, limits the risk of information overload by facilitating an overall understanding of the situation. It becomes possible to decide quickly, if necessary, which new strategies will be robust and reliable.

Because the advantages of meta rules are likely to go beyond CTI situations, they might offer sources of flexibility and reliability in organizations. They can help to resolve different types 
of paradoxes, such as "routine versus adaptation", "structure versus agency" (Feldman \& Pentland, 2003), "empowerment versus control" (Jarzabkowski, et al., 2013) or "learning versus performing" (Garcias, et al., 2015). Metaphorically, meta rules constitute an "abstract grammar" that enables actors to keep the whole system in mind and thereby identify critical factors for its integrity.

\section{Conclusion}

The findings of our research suggest that meta rules represent a possible reliable answer when the time for action does not allow the decision-maker to organize the existing knowledge and/or to conceive new suitable and robust knowledge and when any error in the decision-making process can irreversibly challenge the integrity of the entity driving.

Theoretically speaking, meta rules are a solution to the limits faced by two theoretical approaches in their search for a higher level of reliability; the works underlined in CTI situations and the use of rules and meta rules enables one to get a higher level of reliability showing that HRO recommendations are more relevant compared to the sensemaking approach.

In managerial terms, for the decision-maker, understanding the situation through meta rules at a key time limits the risk of information overload by facilitating an overall understanding of a situation. It becomes possible to decide quickly, if necessary, using robust and reliable strategies. The design of this research contains several limitations (sample size, measure scales, bias due to the conditions of the simulator, the control of our variables), but the results encourage us to further our study by changing the time constraints and also by using experts, as we constructed the design with a population of non-experts, thereby raising interesting issues for future research. 


\section{References}

Anderson, P. (1999). Complexity Theory and Organization Science. Organization Science, 10, 216-232.

Artinger, F., Petersen, M., Gigerenzer, G., \& Weibler, J. (2015). Heuristics As Adaptive Decision Strategies In Management. Journal of Organizational Behavior, 36, S33-S52.

Benitez, J., Henseler, J., \& Castillo, A. (2017). Development and Update of Guidelines to Perform and Report Partial Least Squares Path Modelling, Pacific Asia Conference on Information Systems (PACIS), Langkawi.

Benitez, J. \& Ray, G. (2012). Introducing IT-Enabled Business Flexibility and IT Integration in the Acquirer's M\&A Performance Equation, Proceedings of the 33rd International Conference on Information Systems, Orlando, Florida, pp. 1-21.

Bierly, P.E. III. \& Spender, J.C. (1995). Culture and High Reliability Organizations: The Case of the Nuclear Submarine. Journal of Management, 21, 639-656.

Bingham, C.B. \& Eisenhardt, K.M. (2011). Rational Heuristics: The 'Simple Rules' that Strategists Learn From Process Experience. Strategic Management Journal, 32, 1437-1464.

Boisot, M.A.X. \& McKelvey, B. (2010). Integrating Modernist and Postmodernist Perspectives on Organizations: A Complexity Science Bridge. Academy of Management Review, 35, 415433.

Boudes, T. \& Laroche, H. (2009). Taking Off the Heat: Narrative Sensemaking in Post-crisis Inquiry Reports, Germany, Walter De Gruyter \& Co.

Bourrier, M. (1999). Le Nucléaire à L'épreuve de L'organisation. Presses Universitaires de France.

Bradley, E., Easley, M. \& Stolle, R. (2001). Reasoning About Nonlinear System Identification. Artificial Intelligence, 133, 139-188.

Brady, F.N. (1987). Rules For Making Exceptions To Rules. Academy of Management Review, $12,436-444$.

Brehmer, B. (1992). Dynamic Decision Making: Human Control of Complex Systems. Acta Psychologica, 81, 211-241.

Brown, A.D. (2004). Authoritative Sensemaking in a Public Inquiry Report, Germany,Walter De Gruyter \& Co.

Bunn, M.D. (1994). Key Aspects of Organizational Buying: Conceptualization and Measurement. Journal of the Academy of Marketing Science, 22, 160-169.

Burnes, B. (2005). Complexity Theories and Organizational Change. International Journal of Management Reviews, 7, 73-90.

Cazenave, T. (2003). Metarules To Improve Tactical Go Knowledge. Information Sciences, 154, 173-188.

Cenfetelli, R.T. \& Bassellier, G., xe, ve. (2009). Interpretation of Formative Measurement in Information Systems Research. Mis Quarterly, 33, 689-707.

Chin, W.W. (1998). Issues and Opinion on Structural Equation Modeling. Mis Quarterly, 22, VII-XVI.

Chin, W.W. (2010). How to Write Up and Report PLS Analyses. In V.E. Vinzi, W.W. Chin, J. Henseler \& H. Wang (Eds.), Handbook of Partial Least Squares: Concepts, Methods and Applications (pp. 655-690), Springer.

Cox, M.T. (2005). Metacognition in Computation: A Selected Research Review. Artificial Intelligence, 169, 104-141.

Crozier, M. \& Friedberg, E. (1977). L'acteur et le Système, Seuil. 
Czarniawska-Joerges, B. (1992). Exploring Complex Organizations: A Cultural Perspective, Sage Publications.

Dahlin, K.B., Chuang, Y.-T. \& Roulet, T.J. (2018). Opportunity, Motivation, And Ability To Learn From Failures And Errors: Review, Synthesis, And Ways To Move Forward. Academy of Management Annals, 252-277.

Davis, J.P., Eisenhardt, K.M. \& Bingham, C.B. (2009). Optimal Structure, Market Dynamism, and the Strategy of Simple Rules. Administrative Science Quarterly, 54, 413-452.

Davis, R. (1980). Meta-rules: Reasoning About Control. Artificial Intelligence, 15, 179-222.

Davis, R., Buchanan, B. \& Shortliffe, E. (1977). Production Rules as a Representation for a Knowledge-based Consultation Program. Artificial Intelligence, 8, 15-45.

Eberl, P., Geiger, D. \& Asslaender, M.S. (2015). Repairing Trust in an Organization after Integrity Violations: The Ambivalence of Organizational Rule Adjustments. Organization Studies, 36, 1205-1235.

Elstein, A.S. (1999). Heuristics and Biases: Selected Errors in Clinical Reasoning. Academic Medicine, 74, 791-794.

Endsley, M.R. (2001). Designing for Situation Awareness in Complex Systems., Proceedings of the Second International Workshop on Symbiosis of Humans, Artifacts and Environment. Kyoto, Japon.

Faraj, S. \& Xiao, Y. (2006). Coordination in Fast-Response Organizations. Management Science, 52, 1155-1169.

Feldman, M.S. \& Pentland, B.T. (2003). Reconceptualizing Organizational Routines as a Source of Flexibility and Change. Administrative Science Quarterly, 48, 94-118.

Fuller, T., Argyle, P. \& Moran, P. (2009). Meta-Rules for Entrepreneurial Foresight. In H. Tsoukas \& J. Shepherd (Eds.), Managing the Future: Foresight in the Knowledge Economy, John Wiley \& Sons.

Garcias, F., Dalmasso, C. \& Sardas, J-C. (2015). Paradoxical Tensions in Learning Processes : Exploration, Exploitation and Exploitative Learning.M@n@gement, 18, 156-178.

Gefen, D., Straub, D. \& Boudreau, M. (2000). Structural Equation Modelling and Regression: Guidelines For Research Practice. Communications of the Association for Information Systems, pp. 1-77.

Goldstein, D.G. \& Gigerenzer, G. (2009). Fast and Frugal Forecasting. International Journal of Forecasting, 25, 760-772.

Guarnieri, F. \& Travadel, S. (2018). Un Récit de Fukushima. Le Directeur Parle, Presses Universitaires de France.

Haenlein, M. \& Kaplan, A.M. (2004). A Beginner's Guide to Partial Least Squares Analysis. Understanding Statistics, 3, 283-297.

Hair, J.F., Black, W.C. \& Babin, B.J. (2010). Multivariate Data Analysis: A Global Perspective, Pearson Education.

Halford, G.S., Wilson, W.H. \& Phillips, S. (1998). Processing Capacity Defined by Relational Complexity: Implications for Comparative, Developmental, and Cognitive Psychology. Behavioral and Brain Sciences, 21, 803-+.

Hayes, A.F. (2017). Introduction to Mediation, Moderation, and Conditional Process Analysis, Second Edition: A Regression-Based Approach, Guilford Publications.

Henseler, J., Hubona, G. \& Ray, P.A. (2016). Using PLS Path Modeling in New Technology Research: Updated Guidelines. Industrial Management \& Data Systems, 116, 2-20.

Jarzabkowski, P., Lê, J. \& Van de Ven, A.H. (2013). Responding to Competing Strategic Demands: How Organizing, Belonging, and Performing Paradoxes Coevolve. Strategic Organization, 11, 245-280. 
Journé, B. (1999). Les Organisations Complexes A Risques: Gerer La Surete Par Les Ressources Etude De Situations De Conduite De Centrales Nucleaires. Ecole Polytechnique, [S.1.], p. 429.

Journé, B. \& Raulet-Croset, N. (2008). Le Concept de Situation: Contribution à L'analyse de L'activité Managériale Dans un Contexte D'ambiguïté et D'incertitude.M@n@gement, 11,2755 .

Klein, G. (1999). Sources of Power: How People Make Decisions, Boston, The MIT Press.

Kœnig, G., Vandangeon-Derumez, I., Marty, M.-C., Auroy, Y. \& Dumond, J.-P. (2016). Compliance With Basic Rules: The Challenge of Dialogical, Enabling Ans Disciplinary Management.M@n@gement, 19, 1-45.

Laporte, T.R. \& Consolini, P.M. (1991). Working in Practice But Not in Theory: Theoretical Challenges of "High-Reliability Organizations". Journal of Public Administration Research \& Theory, 1.

Leal-Rodríguez, A.L., Roldán, J.L., Ariza-Montes, J.A. \& Leal-Millán, A. (2014). From Potential Absorptive Capacity to Innovation Outcomes in Project Teams: The Conditional Mediating Role of the Realized Absorptive Capacity in a Relational Learning Context. International Journal of Project Management, 32, 894-907.

Leveson, N., Dulac, N., Marais, K. \& Carroll, J. (2009). Moving beyond Normal Accidents and High Reliability Organizations: A Systems Approach to Safety in Complex Systems. Organization Studies, 30, 227-249.

Lipshitz, R., Klein, G., Orasanu, J. \& Salas, E. (2001). Focus Article: Taking Stock of Naturalistic Decision Making. Journal of Behavioral Decision Making, 14, 331-352.

Maitland, E. \& Sammartino, A. (2015). Decision Making and Uncertainty: The Role of Heuristics and Experience in Assessing a Politically Hazardous Environment. Strategic Management Journal, 36, 1554-1578.

McKelvey, B. (1997). Quasi-natural Organization Science. Organization Science: A Journal of the Institute of Management Sciences, 8, 351-380.

McKelvey, B. (1999). Complexity Theory in Organization Science: Seizing the Promise or Becoming a Fad? Emergence, 1, 5.

Ouchi, W. G. (1980). Markets, Bureaucracies, and Clans. Administrative Science Quarterly, 129.

Petter, S., Straub, D. \& Rai, A. (2007). Specifying Formative Constructs in Information Systems Research. Mis Quarterly, 31, 623-656.

Preacher, K.J. \& Hayes, A.F. (2004). SPSS and SAS Procedures for Estimating Indirect Effects in Simple Mediation Models. Behavior Research Methods, Instruments, \& Computers, 36, 717 731.

Rasmussen, J. (1983). Skills, Rules, And Knowledge - Signals, Signs, And Symbols, And Other Distinctions In Human-Performance Models. Ieee Transactions on Systems Man and Cybernetics, 13, 257-266.

Roberts, K.H. (1990). Managing High Reliability Organizations. California Management Review, 32, 101-113.

Roberts, K.H. \& Rousseau, D.M. (1989). Research in Nearly Failure-Free, High-Reliability Organizations - Having The Bubble. IEEE Transactions on Engineering Management, 36, 132139.

Roberts, K.H., Stout, S.K. \& Halpern, J.J. (1994). Decision Dynamics in Two High Reliability Military Organizations. Management Science, 40, 614-624.

Rochlin, G.I. (1996). Reliable Organizations: Present Research and Future Directions. Journal of Contingencies \& Crisis Management, 4, 55.

Romelaer (1998). Les Règles dans les Organisations. In Thépot (Ed.), Gestion et Théorie des Jeux - L'interaction Stratégique dans la Décision, Vuibert. 
Rosen, M.A., Salas, E., Lyons, R. \& Fiore, S.A. (2012). Expertise and Naturalistic Decision Making in Organizations: Mechanisms of Effective Decision Making. In G. P. Hodgkinson, \& W. H. Starbuck (Eds.), The Oxford Handbook of Organizational Decision Making, Oxford Oxford University Press.

Saleh, J.H., Marais, K.B., Bakolas, E. \& Cowlagi, R.V. (2010). Highlights from the Literature on Accident Causation and System Safety: Review of Major Ideas, Recent Contributions, and Challenges. Reliability Engineering and System Safety, 95, 1105-1116.

Sterman, J.D. (1994). Learning In and About Complex Systems. System Dynamics Review, 10, 291-330.

Sutcliffe, K.M. \& Weick, K.E. (2006). Managing the Unexpected: Assuring High Performance in an Age of Complexity, Wiley India Pvt. Limited.

Tenenhaus, M., Vinzi, V.E., Chatelin, Y.-M. \& Lauro, C. (2005). PLS Path Modeling. Computational Statistics \& Data Analysis, 48, 159-205.

van der Vegt, G.S., Essens, P., Wahlström, M. \& George, G. (2015). Managing Risk and Resilience. Academy of Management Journal, 971-980.

Weick, K. E. (1995). Sensemaking in Organizations, Sage Publications.

Weick, K.E. (1987). Organizational Culture as a Source of High Reliability. California Management Review, 29, 112-127.

Weick, K.E. (1993). The Collapse of Sensemaking in Organizations: The Mann Gulch Disaster. Administrative Science Quarterly, 38, 628-652.

Weick, K.E. (1998). Introductory Essay: Improvisation as a Mindset for Organizational Analysis. Organization Science, 9, 543-555.

Weick, K.E. (2001). Making Sense of the Organization, Blackwell Publishing.

Weick, K.E. \& Sutcliffe, K.M. (2006). Mindfulness and the Quality of Organizational Attention. Organization Science, 514.

Weick, K.E. \& Sutcliffe, K.M. (2011). Managing the Unexpected: Resilient Performance in an Age of Uncertainty, Wiley.

Weick, K.E., Sutcliffe, K.M. \& Obstfeld, D. (2005). Organizing and the Process of Sensemaking. Organization Science, 16, 409-421.

Yami, S., Chappert, H. \& Mione, A. (2015). Strategic Relational Sequences: Microsoft's Coopetitive Game in the OOXML Standardization Process. M@n@gement, 18, 330-356.

Zhao, X., Lynch, J.J.G. \& Chen, Q. (2010). Reconsidering Baron and Kenny: Myths and Truths about Mediation Analysis. Journal of Consumer Research, 37, 197-206. 


\section{APPENDICES}

APPENDIX 1: Items and Evaluation of the Measurement Models

\begin{tabular}{|c|c|c|c|c|c|}
\hline PANEL A: Model 1 & $\mathrm{p}_{\mathrm{A}}$ & AVE & VIF & Weights & Loadings \\
\hline \multicolumn{6}{|l|}{ Construct } \\
\hline \multicolumn{6}{|l|}{ Rule (a) } \\
\hline $\begin{array}{l}\text { During the exercise, the nautical rules have been } \\
\text { applied }\end{array}$ & & & 3.655 & $0.445^{* * *}$ & $0.949 * * *$ \\
\hline F1 applied the rules & & & 3.908 & $0.424 * * *$ & $0.951 * * *$ \\
\hline The crew members applied the rules & & & 2.209 & $0.210^{* * *}$ & $0.826 * * *$ \\
\hline \multicolumn{6}{|l|}{ Meta rule (b) } \\
\hline $\begin{array}{l}\text { Call for the vigilance of the bridge tam members } \\
\text { (verbally or through gestures) }\end{array}$ & & & 1.559 & $0.384 * * *$ & $0.798 * * *$ \\
\hline Reduce the vessel speed & & & 1.439 & 0.236 & $0.698 * * *$ \\
\hline Take visual cues in the environment & & & 1.717 & $0.394 * *$ & $0.842 * * *$ \\
\hline Ask for derogation for the ship's master & & & 1.328 & $0.292 * *$ & $0.675 * * *$ \\
\hline Reliability (c) Cronbach's alpha 0.956 & 0.966 & 0.852 & & & \\
\hline The team reached the goals & & & 4.207 & $0.235^{* * *}$ & $0.914 * * *$ \\
\hline $\begin{array}{l}\text { In a real situation, the action of the team } \\
\text { maintained the vessel in good working condition }\end{array}$ & & & 5.376 & $0.218 * * *$ & $0.927 * * *$ \\
\hline The vessel equipment & & & 6.085 & $0.214 * * *$ & $0.933 * * *$ \\
\hline The vessel crew & & & 4.648 & $0.202 * * *$ & $0.920 * * *$ \\
\hline $\begin{array}{l}\text { The team is able to continue its mission after the } \\
\text { exercise }\end{array}$ & & & 4.449 & $0.216^{* * *}$ & $0.920 * * *$ \\
\hline PANEL B: Model 2 & $\mathrm{p}_{\mathrm{A}}$ & AVE & VIF & Weight & Loading \\
\hline Interaction (d) Cronbach's alpha 0.867 & 0.917 & 0.786 & & & \\
\hline Degree of interactions between $\mathrm{f} 1$ and $\mathrm{f} 2$ & & & 2.531 & $0.432 * * *$ & $0.918 * * *$ \\
\hline $\begin{array}{l}\text { Degree of interactions between } \mathrm{f} 1 \text { and the other } \\
\text { crew members }\end{array}$ & & & 2.188 & $0.422 * * *$ & $0.899 * * *$ \\
\hline $\begin{array}{l}\text { Degree of interactions between } \mathrm{f} 2 \text { and the other } \\
\text { crew members }\end{array}$ & & & 2.156 & $0.266^{* * *}$ & $0.841 * * *$ \\
\hline \multicolumn{6}{|l|}{ Meta rule (b) } \\
\hline $\begin{array}{l}\text { Call for the vigilance of the bridge tam members } \\
\text { (verbally or through gestures) }\end{array}$ & & & 1.559 & $0.632 * * *$ & $0.907 * * *$ \\
\hline Reduce the vessel speed & & & 1.432 & 0.033 & $0.547 * * *$ \\
\hline Take visual cues from the environment & & & 1.717 & $0.316^{* *}$ & $0.801 * * *$ \\
\hline
\end{tabular}




\begin{tabular}{|l|l|l|l|l|l|}
\hline Ask for derogation for the ship's master & & & 1.328 & $0.259 * *$ & $0.599 * * *$ \\
\hline Reliability (c) Cronbach's alpha 0.956 & 0.966 & 0.786 & & & \\
\hline The team reached the goals & & & 4.207 & $0.241 * * *$ & $0.916 * * *$ \\
\hline $\begin{array}{l}\text { In a real situation, the action of the team } \\
\text { maintained the vessel in good working condition }\end{array}$ & & & 5.372 & $0.212^{* * *}$ & $0.925 * * *$ \\
\hline $\begin{array}{l}\text { The vessel equipment } \\
\text { The vessel crew }\end{array}$ & & & 6.085 & $0.197 * * *$ & $0.930 * * *$ \\
\hline $\begin{array}{l}\text { The team is able to continue its mission after the } \\
\text { exercise }\end{array}$ & & & 4.648 & $0.205 * * *$ & $0.920 * * *$ \\
\hline
\end{tabular}

Note: Dijstra and Henseler's rho (pA), Average Variance Extracted (AVE), Variance Inflation Factor (VIF); ${ }^{*} p<0.05,{ }^{*} \mathrm{p}<0.01, * * * \mathrm{p}<0.001$, one-tailed test. Model 1: SRMR: 0.052; Model 2: SRMR: 0.068

(a) "Rule" variable is measured from a five-point Likert scale (1 strongly disagree; 5 strongly agree).

(b) "Meta rules" variable is measured from a five-point Likert scale relative to the use of meta rules (1 strongly disagree; 5 strongly agree).

(c) "Reliability" variable is measured from a five-point Likert scale (1 strongly disagree; 5 strongly agree).

(d) "Interactions" variable is measured from a five-point semantic scale (1 very low; 5 very high).

Discriminant validity evaluation based on Fornell-Larcker criterion Model 2

\begin{tabular}{|l|l|l|}
\hline & Reliability & Interactions \\
\hline Reliability & 0.923 & \\
\hline Interaction & 0.723 & 0.887 \\
\hline
\end{tabular}

Note: Diagonal row presents the square roof of the AVE. 
APPENDIX 2 : Correlations and descriptive statistics

\begin{tabular}{|c|c|c|c|c|c|c|c|c|c|c|c|c|c|c|c|c|c|c|}
\hline Items & Mean & $\begin{array}{c}\text { Standard } \\
\text { Deviation }\end{array}$ & $\mathrm{q} 1$ & $\mathrm{q} 2$ & $\mathrm{q} 3$ & q81 & q82 & q83 & q84 & q29 & q301 & q302 & q303 & $\mathrm{q} 32$ & $\mathrm{q} 22$ & $\mathrm{q} 23$ & q24 & $\mathrm{q} 25$ \\
\hline q1 rule & 3,519 & 1,148 & 1 & & & & & & & & & & & & & & & \\
\hline q2rule & 3,481 & 1,131 & $0,842^{* *}$ & 1 & & & & & & & & & & & & & & \\
\hline q3rule & 3,435 & 1,070 & $0,697^{* *}$ & $0,721 * *$ & 1 & & & & & & & & & & & & & \\
\hline q81metaru & 0,565 & 0,498 & 0,431 ** & $0,541 * *$ & $0,464 * *$ & 1 & & & & & & & & & & & & \\
\hline q82metaru & 0,648 & 0,480 & $0,250^{* *}$ & $0,315^{* *}$ & $0,283 * *$ & $0,409 * *$ & 1 & & & & & & & & & & & \\
\hline q83metaru & 0,519 & 0,502 & $0,583^{* *}$ & $0,527 * *$ & $0,463 * *$ & $0,575^{* *}$ & $0,454^{* *}$ & 1 & & & & & & & & & & \\
\hline q84metaru & 0,713 & 0,454 & $0,413^{* *}$ & $0,326 * *$ & $0,375 * *$ & $0,310^{* *}$ & $0,433^{* *}$ & $0,413 * *$ & 1 & & & & & & & & & \\
\hline q29relia & 3,352 & 1,240 & $0,796^{* *}$ & $0,797 * *$ & $0,728 * *$ & $0,522^{* *}$ & $0,383^{* *}$ & $0,560 * *$ & $0,396^{* *}$ & 1 & & & & & & & & \\
\hline q301 relia & 3,426 & 1,087 & $0,773^{* *}$ & $0,751 * *$ & $0,594 * *$ & $0,501 * *$ & $0,308^{* * *}$ & $0,499 * *$ & $0,401 * *$ & $0,775^{* *}$ & 1 & & & & & & & \\
\hline q302relia & 3,481 & 1,072 & 0,760 ** & $0,755^{* *}$ & $0,606 * *$ & 0,466 ** & $0,260^{\text {*** }}$ & $0,383 * *$ & $0,363^{* *}$ & $0,778^{* *}$ & $0,881^{* *}$ & 1 & & & & & & \\
\hline q303relia & 3,528 & 1,063 & $0,685^{* *}$ & $0,711^{* *}$ & $0,593 * *$ & $0,491 * *$ & $0,276^{* * *}$ & $0,446 * *$ & $0,316^{* * *}$ & $0,815^{* *}$ & $0,807^{* *}$ & $0,849 * *$ & 1 & & & & & \\
\hline q32relia & 3,657 & 1,069 & $0,740^{* *}$ & $0,717 * *$ & $0,622 * *$ & $0,577 * *$ & $0,400^{* *}$ & $0,508 * *$ & $0,430^{* * *}$ & $0,832 * *$ & $0,818^{* *}$ & $0,806 * *$ & $0,785^{* *}$ & 1 & & & & \\
\hline q22interac & 2,972 & 1,172 & $0,622 * *$ & $0,659 * *$ & $0,703 * *$ & $0,524 * *$ & $0,332 * *$ & $0,438 * *$ & $0,318^{* *}$ & $0,733^{* *}$ & $0,640^{* *}$ & $0,599 * *$ & $0,635^{* *}$ & $0,679 * *$ & 1 & & & \\
\hline q23interac & 2,991 & 1,037 & $0,656^{* *}$ & $0,697 * *$ & $0,669 * *$ & $0,517 * *$ & $0,313^{* *}$ & $0,458 * *$ & $0,312 * *$ & $0,715^{* *}$ & $0,609^{* *}$ & $0,610^{* * *}$ & $0,590^{* *}$ & $0,646^{* *}$ & $0,708^{* * *}$ & 1 & & \\
\hline q24interac & 2,676 & 1,159 & $0,423 * *$ & $0,441 * *$ & $0,575 * *$ & $0,353 * *$ & 0,096 & $0,211^{*}$ & 0,123 & $0,503 * *$ & $0,385^{* *}$ & $0,360 * *$ & $0,421 * *$ & $0,430^{* *}$ & $0,702 * *$ & $0,643 * *$ & 1 & \\
\hline q25complex & 3,380 & 0,944 & 0,093 & 0,090 & $0,233^{*}$ & 0,116 & $0,318^{* * *}$ & 0,172 & $0,278 * *$ & $0,260 * *$ & 0,141 & 0,187 & 0,106 & $0,250^{* *}$ & 0,179 & 0,099 & 0,028 & 1 \\
\hline
\end{tabular}


Dr Sophie Le Bris is a senior lecturer at the French Naval Academy where she is responsible for the academic leadership training in the Humanities Department. Her research focuses on reliability, decision-making process in complex situations and meta-rules developed through European projects, communications for AIMS, EGOS, chapters on decision-making. She also provides her expertise to Naval forces. In 2018, she founded the chair "Resilience \& Leadership" that she leads as holder with Pr Martin.

Dr. Antonia Madrid-Guijarro is an Associate Professor of Financial Economics and Accounting at Universidad Politécnica de Cartagena-UPCT (Spain). She is in charge of research activities of the Office for Entrepreneurs and Spin-off Firms of UPCT. She is a researcher at the Economic Observatory of SMEs in the Region of Murcia and at FAEDPYME. Her research topics are related to accounting and finance in Small and Medium Sized Enterprises (SME), entrepreneurship, efficiency assessment and factors that influence innovation and internationalization, financing constraints at SME and networking. Madrid-Guijarro has published in the following journals: Journal of Small Business Management, Journal of Entrepreneurship and Regional Development and Spanish Accounting Journal, among others.

Dr Dominique Philippe MARTIN is Professor of HRM and Innovation Management at the Graduate School of Business and Administration of the University of Rennes (FRANCE) and member of the CREM - UMR CNRS 6211. His research covers the areas of decision-making and leadership in complex environments, strategy of SMEs and knowledge transfer from Universities. He works as expert for French Navy and has published extensively in English and French management journals such as Technological Forecasting and Social Change, Journal of High Technology Management Research, Finance Contrôle Stratégie, Revue de Gestion des Ressources Humaines. He is co-holder of the "Resilience \& Leadership" chair with Dr. Sophie Le Bris. 